\section{Biochemical Attributes of Amniotic Fluid during Fetal Growth Stage of Successful Pregnancy in Rabbits}

\author{
Hamayun Khan ${ }^{1, *}$, Abdul Wahab ${ }^{1}$, Navaid Kazi², Younas Muhammad', \\ Summaya Kazi ${ }^{3}$, Salman Kazi ${ }^{4}$, Azmatullah Khan ${ }^{1}$, Ikramullah Khan ${ }^{5}$ and \\ Shakoor Ahmad ${ }^{1}$ \\ ${ }^{1}$ Department of Animal Health, The University of Agriculture, Peshawar \\ ${ }^{2}$ Department of Physiology, ISRA University, Hyderabad \\ ${ }^{3}$ Department of Biochemistry, ISRA University, Hyderabad \\ ${ }^{4}$ Department of Forensic Medicine, ISRA University, Hyderabad \\ ${ }^{5}$ Directorate of Livestock and Dairy Development, Peshawar
}

\begin{abstract}
A B S T R A C T
The aim of this study was to assess biochemical markers of rabbit amniotic fluid during fetal growth stage of successful pregnancy. Experiments were executed on 15 pregnant rabbits at three different time point of successful pregnancy i.e. day 18 , day 25 and day 28 with commercially accessible kits for biochemical markers that includes glucose, total protein, albumin, creatinine, triglycerides, blood urea nitrogen (BUN), alanine transaminase (ALT) and aspartate transaminase (AST). The current study demonstrated the ascertained value in amniotic fluid for glucose, total protein and albumin at day 18, 25 and 28 was $42.9 \pm 0.80, \quad 37.4 \pm 0.90, \quad 36.5 \pm 0.88 \mathrm{mg} / \mathrm{dl} ; \quad 17.9 \pm 0.30, \quad 16.1 \pm 0.22, \quad 13.9 \pm 0.34 \mathrm{~g} / \mathrm{l} ; \quad 13.9 \pm 1.6,11.5 \pm 0.75$, $8.8 \pm 0.15 \mathrm{~g} / \mathrm{I}$ whereas that of creatinine, triglyceride, BUN, ALT and AST at the corresponding days of pregnancy were $1.5 \pm 0.1,1.6 \pm 0.2,1.7 \pm 0.15 \mathrm{mg} / \mathrm{dl} ; 6.06 \pm 0.15,4.6 \pm 1.2,3.2 \pm 0.8 \mathrm{mg} / \mathrm{dl}, 13.1 \pm 0.02$, $14.2 \pm 0.3,18.5 \pm 0.3 \mathrm{mg} / \mathrm{dl} ; 36.5 \pm 0.6,32.8 \pm 0.5,17.3 \pm 1.2 \mathrm{IU} / 1 ; 7.9 \pm 1.3,8.7 \pm 0.4,14.8 \pm 1.9 \mathrm{IU} / 1$. During current study, glucose, total protein, Albumin, triglyceride and ALT was significantly down regulated whereas creatinine, BUN, and AST was up regulated in the amniotic fluid at the end of fetal growth of successful pregnancy in rabbits.
\end{abstract}

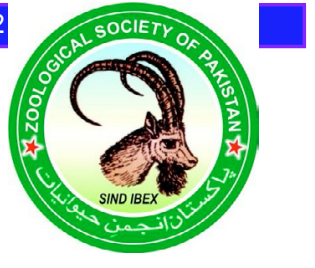

CrossMark

Article Information
Received 23 July 2017
Revised 12 December 2017
Accepted 07 January 2018
Available online 21 May 2018
Authors' Contribution
HK conceived the idea of the research
and wrote the manuscript. AW carried
out the experimental work and YM,
Summaya K and Salman K helped
hiim. AK and IK helped in the execu-
tion of the experiments. SA and NK
analysed of the data statically.
Key words
Amniotic fluid, Biochemical markers,
Fetal growth stage, Rabbit.

Revised 12 December 2017

Accepted 07 January 2018

Authors' Contribution

and wrote the the idea of the research

out the experimental work and YM,

Summaya $\mathrm{K}$ and Salman $\mathrm{K}$ helped

tion of the experiments.

analysed of the data statically.

Fetal growth stage, Rabbit.

\section{INTRODUCTION}

$\mathrm{F}$ ast expansion in human population has been associated with reduced protein intake in the developing countries and great variation has been observed in its consumption despite the fact that animal origin protein are considered essential portion of the human foodstuff (Okai et al., 2005). Rabbit farming has a substantial prospective for the provision of the most animal protein in the developing world based on reduced cost and space provision. Additionally the reproductive activities such as small pregnancy period, fast growing growth speed, high proliferation and usage of agricultural offshoot, make the rabbit farming the most suitable enterprise for the subsistence of the low income people in the developing countries (Cheeke, 1986). Meat production is the most important aspect of rabbit production and rabbit's meat is a good source of animal protein for human beings. Due to low value of cholesterol,

\footnotetext{
Corresponding author: hamayunkhan@aup.edu.pk 0030-9923/2018/0004-1307 \$ 9.00/0

Copyright 2018 Zoological Society of Pakistan
}

50g/100g; fat, 4g/100g; energy, $124 \mathrm{kcal} / 100 \mathrm{~g}$ rabbit meat is a source of healthful food but high in protein, $22 \mathrm{~g} / 100 \mathrm{~g}$.

Rabbit is most extensively utilized mammalian model used in the field of reproduction and developmental biology and/or biotechnologies such as cloning. A key feature of rabbit as animal model is its applicability to the human condition. Since both rabbit and human have the same hemochorial type of placenta (Chesne et al., 2002). Fetal fluid is prerequisite for efficient connections between fetal and maternal tissues, as fetal fluids prevents developing fetus from any mechanical shock during gestational period (Amle et al., 1992; Khadjeh et al., 2007). The fetus is surrounded by exclusive aqueous amniotic fluid sac during the entire gestational period. Major part of the amniotic fluid may be proteins and metabolites produced by amniotic cells, placental tissues, and excretion of the developing fetus (Moore 1982; Hammer et al., 1997; Pelizzo et al., 1914). Recently it has been reported that organic substances like total protein in the amniotic fluid has been associated with modulation of the developmental process of growing fetus (Tong et al., 2009). Little information is available on the reproductive 
characteristics of the rabbit fundamentally pertaining to amniotic fluid composition. Therefore the comprehensive and detail description of the biochemical aspects of the amniotic fluid is essential for better understanding of the fetal metabolism that would ultimately be helpful for the accurate assessment of alteration in the fetal metabolism and other associated anatomical or pathophysiological abnormalities during fetal growth stage (Prestes et al., 2001).

The domestic rabbit (Oryctolagus cunniculus) is an important non-ruminant herbivore for meat production. Improvement of the reproductive management of the local rabbits would proficiently make better its production under backyard production system. Furthermore enhancement of the reproductive efficiency of local rabbits is our incessant task with provision of maternal nutrient supply at the different reproductive stages of pregnancy. To increase the reproductive efficiency and productive performance of the local rabbits, regular monitoring of the reproductive status with provision of essential nutrients including the glucose, lipid and protein is fundamental during developmental stages of pregnancy since the growth of developing fetus depends upon these nutrients. Currently we have reported biochemical profile of $O$. cuniculus during successful pregnancy under backyard production system (Wahab et al., 2016). Since different stages of development during pregnancy have an effect on the glucose, protein and other biochemical indicators in rabbits for the growth of the developing fetus. The sequential biochemical profile of the amniotic fluid during placentation and fetal growth stages of pregnancy are not yet been fully reported despite the study of Ozegbe (2005) that has been carried out at full term. Consequently, our study has been carried out for elucidation of the reference biochemical values for selected biochemical constituents in the amniotic fluid at the end of placentation period and fetal growth stages of pregnancy in the local rabbits under the existing management system.

\section{MATERIAL AND METHODS}

Investigation of the current research project and the use of experimental animal were in accordance with the approval of ethics committee of Faculty of Animal Husbandry and Veterinary Science, the University of Agriculture, Peshawar. Experiments were carried out on 15 nondescript pregnant local rabbits at fixed time point (i.e. at day 18 (5 rabbits), day 25 (5 rabbits) and day 28 (5 rabbits)) of successful pregnancy. The mating date was considered as day 0 of the pregnancy. Theses experimental rabbits were purchased from rabbit breeders/ farmers at the open market having the standard breeding or reproduction facility for reproductive management of theses rabbits under normal condition. The auricular ear vein of the experimental rabbits was used for collection of the blood aseptically at specified days of pregnancy. After blood sample collection from the auricular vein, rabbits were sacrificed by the intravenous injection of $130 \mathrm{mg} / \mathrm{kg}$ pentobarbital sodium. Intact fetuses along with placentas and amniotic fluid were collected as per standard protocol. For collection of amniotic fluid, the abdomen of the experimental rabbits at day 18, 25 and 28 were was aseptically prepared. Mid line incision was made on the skin to approach the pregnant uterus. The gravid uterine were cut open at dorsal curvature without damaging the fetal sac. The amniotic fluids were collected with $5 \mathrm{ml}$ sterilized disposable syringes of $22 \mathrm{G}$ and 1 inch needle (Nisa) and stored in labeled plastic eppendorf tubes (Capacity $1.5 \mathrm{ml}$ ) at $-18^{\circ} \mathrm{C}$ to $-20^{\circ} \mathrm{C}$ until the assessment for biochemical indicators (Tabatabaei, 2011; BananKhojasteh, 2011).

Commercially available kits (Reactivos GPL, Chemelex, S.A. Barcelona, Spain) was used for assessment of selected biochemical indicators i.e. glucose, total protein, albumin, blood urea nitrogen (BUN), triglyceride, creatinine, alanine transaminase (ALT) and aspartate transaminase (AST) in amniotic fluid of the experimental rabbits.

\section{Statistical analysis}

Deliberation of the selected biochemical indicators were statistically carried out using the mean values $( \pm \mathrm{SE})$. Data on biochemical aspects in amniotic fluid at different time point of gestation were expressed as Mean \pm SE. One way ANOVA (analysis of variance) in SPSS (Statistical Package for the Social Sciences) version 16 for windows (SPSS Inc., Chicago, IL, USA) were applied to look at the level of variation in biochemical indicators in amniotic fluid at placentation and fetal growth stage of pregnancy. The level of significance between means was carried out with Duncan's multiple range tests. $\mathrm{P}<0.05$ was used for Statistical significance.

\section{RESULTS}

The current study established the values for selected biochemical indicator in the amniotic fluid as under: glucose concentration at day 18,25 and 28 was $42.9 \pm 0.80$, $37.4 \pm 0.90,36.5 \pm 0.88 \mathrm{mg} / \mathrm{dl}$; total protein and albumin at the corresponding days were $17.9 \pm 0.30,16.1 \pm 0.22$, $13.9 \pm 0.34 \mathrm{~g} / \mathrm{l} ; 13.9 \pm 1.6,11.5 \pm 0.75,8.8 \pm 0.15 \mathrm{~g} / \mathrm{I}$. Likewise that of creatinine and triglyceride at day 18,25 and 28 day were $1.5 \pm 0.1,1.6 \pm 0.2,1.7 \pm 0.15 \mathrm{mg} / \mathrm{dl} ; 6.06 \pm 0.15$, $4.6 \pm 1.2,3.2 \pm 0.8 \mathrm{mg} / \mathrm{dl}$ whereas BUN, ALT and AST at the analogous days of gestation were, $13.1 \pm 0.02,14.2 \pm 0.3$, 
$18.5 \pm 0.3 \mathrm{mg} / \mathrm{dl} ; \quad 36.5 \pm 0.6, \quad 32.8 \pm 0.5,17.3 \pm 1.2 \quad \mathrm{IU} / \mathrm{l} ;$ $7.9 \pm 1.3,8.7 \pm 0.4,14.8 \pm 1.9 \mathrm{IU} / 1$ (Table I). During current investigation level of glucose, total protein, albumin and triglyceride was significantly decreased at the end of fetal growth stage (day28) in the amniotic fluid in comparison with placentation period (day18), whereas BUN and AST levels were significantly increased during corresponding period of the flourishing pregnancy.

Table I.- Some biochemical componenets (Mean \pm SE) of amniotic fluid at fetal growth stage of successful pregnancy in local rabbits.

\begin{tabular}{lccc}
\hline \multirow{2}{*}{$\begin{array}{l}\text { Biochemical } \\
\text { constituents }\end{array}$} & \multicolumn{3}{c}{$\begin{array}{c}\text { Fetal growth stage of } \\
\text { successful pregnancy }\end{array}$} \\
\cline { 2 - 4 } & Day 18 & Day 25 & Day 28 \\
\hline Glucose (mg/dl) & $42.9 \pm 0.8^{\mathrm{a}}$ & $37.4 \pm 0.9^{\mathrm{b}}$ & $36.1 \pm 0.1^{\mathrm{b}}$ \\
Total protein (g/l) & $17.9 \pm 0.3^{\mathrm{a}}$ & $16.1 \pm 0.2^{\mathrm{b}}$ & $13.9 \pm 0.3^{\mathrm{c}}$ \\
Albumin (g/l) & $13.9 \pm 1.6^{\mathrm{a}}$ & $11.5 \pm 0.75^{\mathrm{b}}$ & $8.8 \pm 0.5^{\mathrm{c}}$ \\
Creatinine (mg/dl) & $1.5 \pm 0.1^{\mathrm{b}}$ & $1.6 \pm 0.1^{\mathrm{ab}}$ & $1.7 \pm 0.15^{\mathrm{a}}$ \\
Triglycerides (mg/dl) & $6.06 \pm 0.15^{\mathrm{bc}}$ & $4.6 \pm 1.2^{\mathrm{a}}$ & $3.2 \pm 0.8^{\mathrm{c}}$ \\
BUN (mg/dl) & $13.1 \pm 0.02^{\mathrm{c}}$ & $14.2 \pm 0.3^{\mathrm{b}}$ & $18.5 \pm 0.3^{\mathrm{a}}$ \\
ALT (IU/l) & $36.5 \pm 0.6^{\mathrm{a}}$ & $32.8 \pm 0.5^{\mathrm{b}}$ & $17.3 \pm 1.2^{\mathrm{c}}$ \\
AST (IU/l) & $7.9 \pm 1.3^{\mathrm{b}}$ & $8.7 \pm 0.4^{\mathrm{b}}$ & $14.8 \pm 1.9^{\mathrm{a}}$ \\
\hline
\end{tabular}

Different superscript $(\mathrm{a}-\mathrm{c})$ in a row differ significantly $(\mathrm{P}<0.05)$ in the amniotic fluid during fetal growth stage of pregnancy. Day 18 is the completion of placentation period that is followed by fetal growth stage. Day28 is the end of fetal growth stage in rabbit successful pregnancy. ALT, alanine transaminase; AST, aspartate transaminase; BUN, blood urea nitrogen

\section{DISCUSSION}

During current investigation, the amniotic fluid biochemical profile has been elucidated at different time point of successful pregnancy i.e. day 18, 25 and 28 . These days of the successful pregnancy play vital role in rabbit reproduction. The reproductive significance of these days is manifold; day 18 is the completion of placentation period in the rabbits and the placenta become matured. This is the period in the rabbit gestation, during which the organogenesis of the developing fetus is maximum and subsequently followed by fetal growth till the termination of gestation. Also this is the period of the extensive organogenesis in the rabbits. Additionally, prenatal death or mortality or intrauterine growth retardation (IUGR) occur during theses period of the successful pregnancy that has been reported in the recent past (Sharma et al., 2016; Vicente et al., 2011). Vicente et al. (2011) reported three critical moments for continued existence of growing fetus during the rabbit pregnancy, the first between days
8 and 17 of pregnancy, which is the implantation and placentation period during which the nutrition of the fetus commence to be controlled by the placenta from the maternal blood circulation (Adam, 1960). A second critical moment when mortality are maximum arise between 17 and 24, corresponding with the fetal growth, when the pressure on the conceptus is at a peak and blood flowing through the maternal vessels of the uterus decreases (Hafez and Tsutsumi, 1966). The third critical moment has been associated with the last week of pregnancy, at that time the energy essentiality for the fetal growth increase speedily whereas the ingestion of feed declines in the days prior to parturition (Fortune-Lamothe, 2006). Hence a disarray of amniotic biochemical profile might be a fatal risk and essential pathway for successful pregnancy. Therefore, elucidation of the factors that might be responsible for prenatal losses and intrauterine growth retardation is very important for enhancement of rabbit production under backyard production system. To our knowledge, we are pioneer to report the sequential biochemical profile of the amniotic fluid during placentation and fetal growth stages of successful pregnancy despite the study of Ozegbe (2005) that has been carried out at full term of rabbit pregnancy. Here in our current study, marked difference has been observed in the concentration of glucose, total protein and other biochemical indicator in amniotic fluid in different physiological stages of the successful pregnancy.

Glucose is essential for fetal development and growth in mammalian species. Concentration of glucose (GLU) in the amniotic fluid during current study indicated significant decrease from end of the period of extensive organogenesis (Day $18^{\text {th }}$ ) to fetal growth stage (Day $28^{\text {th }}$ ). The findings of the current study on the amniotic fluid glucose profile were in line with Reddy et al. (1995) who investigated the significant decreased level of glucose in ewe amniotic fluid at different stages of pregnancy. Additionally, our results about the glucose analysis in amniotic fluid and that we recently published on the maternal blood (Wahab et al., 2016) confirmed the previous report in rabbits that glucose concentration in fetal compartment was significantly decreased compared to that of the mother (Ozegbe, 2005). Taken all theses together including our current findings, it seem reasonable that lowered glucose levels in the amniotic fluid during the fetal growth stage in advancing pregnancy might have been associated with fetal intake of glucose due to the growth of the fetal swallowing reflex (Prestes et al., 2001). Amniotic fluid proteins are considered as nutritional evaluation marker of the normal fetal growth (Tisi et al., 2004). During current study of amniotic fluid, significant decrease has been demonstrated in total protein and albumin level with each succeeding period from placentation period to the end of fetal growth period. 
Khadjeh et al. (2007) elucidated the highest value of total protein in amniotic fluid in the early days of pregnancy followed by decreased with advancing pregnancy stages. The comparatively lower levels of total protein in the amniotic fluid might be due to metabolic activities and the maturation of the fetal kidneys with the advancement of pregnancy (Gulbis et al., 1998). The additional cause of lowered total protein concentration in the amniotic fluid might be ascribed to non availability of the fibrinogen and other related protein because of the immaturity of fetal liver (Reddy et al., 1995).

Recent appraisal of literature demonstrated that liver enzymes of AST and ALT are synthesized by the fetus and its concentration has been reported in the amniotic fluid in diverse mammalian species (Kuczynska-Sicinska et al., 1989; Smolarczyk et al., 1996; Ozegbe, 2005; Kale et al., 2008). Although the physiological definite role of the ALT and AST in the amniotic fluid is not yet clarified, however it has been ascribed to have potential role in supporting the metabolic actions of amnion in rabbits during successful pregnancy (Ozegbe, 2005). Significant decrease that has been observed in our study for ALT concentration in amniotic fluid during the period of organogenesis and fetal growth of the pregnancy were in agreement with the finding of Mahawar et al. (2004), Pouroucholtamane et al. (2005) and Ozegbe (2005) in diverse mammalian species including rabbits.

The current finding further demonstrated significant higher level of the creatinine concentration in amniotic fluid from placentatation period to the end fetal growth stage (d18-28). Since creatinine concentration in the amniotic fluid has been associated with muscle mass of fetus and also used as gauge for the assessment of fetal kidney function in rabbits (Ozegbe, 2005). The increase in creatinine concentration in amniotic fluid might be ascribed to the development of fetal musculature. Our result on creatinine concentration in the amniotic fluid was in line with Anitha and Thangavel (2011) and Prestes et al. (2001). Recently, Anitha and Thangavel (2011) investigated that concentration of creatinine in the ovine amniotic fluid has been increased with advancing pregnancy that might be associated with increased protein metabolism in the developing fetus during corresponding period. Furthermore, Creatinine in amniotic fluid was derivative of the makeover of creatinine into fetal muscle and was an indication of growing fetal muscle mass and fetal glomerular filtration (Chez et al., 1964). Significant low values were recorded in the urea level in the amniotic fluid during placentation period (day 18) whereas significantly higher tendency was noted during fetal growth stage. Our results regarding the urea concentration in the amniotic fluid were in line with recent findings of
Anitha and Thangavel (2011), who observed an increase concentration of urea in the ovine amniotic fluid with advancing pregnancy. The current findings were also corresponded with the description of Anderer and Schinder (1975) that increase concentration of urea in amniotic fluid is mostly determined by fetal micturition in the amniotic cavity. Furthermore, similar results reported by Liteanui $e t$ al. (2009) and Benzie et al. (1974). Liteanui et al. (2009) stated that BUN is an indicator and basic parameter which represents maturity and function of fetal kidneys. Benzie et al. (1974) stated that fetal urine was the major provider of urea to amniotic fluid during advanced pregnancy.

\section{CONCLUSION}

The current pilot study demonstrated the preliminary reference value of the selected biochemical marker in the amniotic fluid during efficient physiological stages of pregnancy under backyard production system. Further elucidation of the biochemical aspects of amniotic fluid with large no of local pregnant rabbits would certainly provide a physiologic gauge that could be utilized essentially for assessment of prenatal mortality and morbidity during advanced stages of successful pregnancy. Hence would eventually enhance reproductive management of local rabbits to increase its productivity under back yard production system to fulfill local meat requirements.

\section{ACKNOWLEDGMENT}

We gratefully acknowledge financial support from Higher education Commission of Pakistan for the execution of this research project.

\section{Statement of conflict of interest}

Authors have declared no conflict of interest.

\section{REFERENCES}

Adams, C.E., 1960. Prenatal mortality in the rabbit oryctolagus cuniculus. J. Reprod. Fertil., 1: 36-44. https://doi.org/10.1530/jrf.0.0010036

Amle, M.B., Chinchkar, S.R., Hukeri, V.B. and Deopurkar, V.L., 1992. Studies on fetal fluids of buffaloes. Indian J. Anim. Res., 13: 165-167.

Anderer, M. and Schindler, A.E., 1975. Creatinine, urea and uric acid in amniotic fluid, maternal and umbilical cord blood at delivery. Arch. Gynak., 220: 65-72. https://doi.org/10.1007/BF00673149

Anitha, A. and Thangavel, A., 2011. Biochemical profile of ovine amniotic and allantoic fluids. Tamilnadu J. Vet. Anim. Sci., 7: 262-267. 
Banan-Khojasteh, S.M., Khadjeh, G.H., Ranjbar, R. and Salehi, M., 2011. Studies on biochemical constituents of goat allantoic fluid during different stages of gestation. Egypt. J. Sheep Goat Sci., 6: $1-5$.

Benzie, R.J., Doran, T.A., Harkins, J.L., Owen V.M.J. and Porter, C.J., 1974. Composition of the amniotic fluid and maternal serum in pregnancy. Am. J. Obset. Gynecol., 119: 799-810. https://doi. org/10.1016/0002-9378(74)90093-3

Cheeke, P.R., 1986. Potentials of rabbit production in tropical and sub-tropical agricultural systems. $J$. Anim. Sci., 63: 1581-1586. https://doi.org/10.2527/ jas1986.6351581x

Chesne, P., Adenot, P.G., Viglietta, C., Baratte, M., Boulanger, L. and Renard, J.P., 2002. Cloned rabbits produced by nuclear transfer from adult somatic cells. Nat. Biotechnol., 20: 366-369. https://doi.org/10.1038/nbt0402-366

Chez, R.A., Smith, Jr. F.G. and Hutchinson, D.L., 1964. Renal function in the intrauterine primate fetus. i. experimental technique; rate of formation and chemical composition of urine. Am. J. Obstet. Gynecol., 90: 128. https://doi.org/10.1016/S00029378(16)34900-6

Fortun-Lamothe, L., 2006. Energy balance and reproductive performance in rabbit does. Anim. Reprod. Sci., 93: 1-15. https://doi.org/10.1016/j. anireprosci.2005.06.009

Gulbis, B., Gervy, C. and Jauniaux, E., 1998. Amniotic fluid biochemistry in second-trimester trisomic pregnancies relationships to fetal organ maturation and dysfunction. Early Hum. Devlop., 52: 211-219. https://doi.org/10.1016/S0378-3782(98)00023-1

Hafez, E.S.E. and Tsutsumi, Y., 1966. Changes in endometrial vascularity during implantation and pregnancy in the rabbit. Am. J. Anat., 118:249-282.

Hammer, A., Hutter, H., Blaschitz, A., Mahnert, W., Hartmann, M., Uchanskaziegler, B., Ziegler, A., and Dor, G., 1997. Amnion epithelial cells, in contrast to trophoblast cells, express all classical HLA class I molecules together with HLA-G. Am. J. Reprod. Immunol., 37: 161-171. https://doi. org/10.1111/j.1600-0897.1997.tb00208.x

Kuczyńska-Sicińska, J., Wójcicka-Jagodzińska, J., Romejko, E., Smolarczyk, R., Siekierski, B.P. and Chodzińska, B., 1989. Biochemical studies of the amniotic fluid in arterial hypertension in relation to intrauterine growth retardation: Parameters of the proteins, lipids, enzymes and renal maturity. Ginekol Pol., 60:266-270.

Kale, E., Umur, K., Ahmet, K., Ali, E. and Naime, C.,
2008. Anew and practical aspartate aminotransferase test in vaginal washing fluid. Fetal Diag. Ther., 24: 425-428. https://doi.org/10.1159/000170093

Khadjeh, G.H., Ranjbar, R., Salehi, M. and BananKhojasteh, S.M., 2007. Biochemical evaluation of amniotic fluid during different stages of gestation in the goat. Iranian J. Vet. Res., 8: 266-269.

Liteanui, A., Violeta, M., Vlad, G. and Vlad, A., 2009. Some biochemical indicators of the amniotic fluid- Possible way for evaluation of the renal development. Scient. Annls. Alexandru Ioan Cuza Genet. Mol. Biol. Section, 10: 14-18.

Mahawar, M., Jain, A.K. and Kumar, P., 2004. Clinically important enzymes in Jamnapari and Marwari goats. Indian J. Anim. Sci., 74: 841-842.

Moore, K.L., 1982. The developing human: Clinically oriented embryology. Saunders, Philadelphia.

Okai, D.B., Abora, P.K.B., Davis, T. and Martin, A., 2005. Nutrient composition, availability, current and potential uses of "Dusa": A cereal by-product obtained from "koko" (porridge) production. J. Sci. Technol., 25: 33-38. https://doi.org/10.4314/just. v25i1.32930

Ozegbe, P.C., 2005. Comparative biochemical assessment of the amniotic fluid and maternal plasma of pregnant rabbits. Vet. Arhiv., 75: 431437.

Pelizzo, G., Ballico, M., Mimmi, M.C., Peirò, J.L., Marotta, M., Federico, C., Andreatta, E., Nakib, G., Sampaolesi, M., Zambaiti, E. and Calcaterra, V., 2014. Metabolomic profile of amniotic fluid to evaluate lung maturity: The diaphragmatic hernia lamb model. Multidiscip. Resp. Med., 9: 54. https:// doi.org/10.1186/2049-6958-9-54

Pourouchottamane, R., Chatterjee, A., Sheikh, I.U., Sarkar, M. and Gogoi, D., 2005. Blood biochemical constituents of female yaks in different physiological status. Indian Vet. J., 82: 1108-1109.

Prestes, N.C., Chalhoub, M.C.L., Lopes, M.D., Takahira, R.K., 2001. Amniocentesis and biochemical evaluation of amniotic fluid in ewes at 70, 100 and 145 days of pregnancy. Small Rumin. Res., 39: 277-281. https://doi.org/10.1016/S09214488(00)00202-9

Reddy, A.P., Reddy, V.S.C., Rao, A.S., Sharma, G.P., Reddy, G.V.N., Reddy, T.J. and Reddy, V.S., 1995. Biochemical studies in the ewe (Ovis aries) amniotic fluid during different stages of gestation. Int. J. Anim. Sci., 10: 321-323.

Sharma, D., Sharma, P. and Shastri, S., 2016. Postnatal complications of intrauterine growth restriction. $J$. Neonatal Biol., 5: 232. 
Smolarczyk, R., Wojcicka-Jagodzinska, J., Romejko, E., Czajkowski, K., Piekarski, P., TeligaCzajkowska, J. and Kuczynska-Sicinska, J., 1996. Evaluation of fetal condition in pregnancy complicated by hypertension, biochemical assessment of amniotic fluid. Enzymes Ginekol. Pol., 67: 598-602.

Tabatabaei, S., 2011. Gestational variations in the biochemical composition of the fetal fluids and maternal blood serum in goat. Comp. Clin. Pathol., 21: 1305-1312. https://doi.org/10.1007/s00580011-1286-4

Tisi, D.K., Emard, J.J. and Koski, K.G., 2004. Total protein concentration in human amniotic fluid is negatively associated with infant birth weight. $J$. Nutr., 134:1754-1758. https://doi.org/10.1093/ jn/134.7.1754
Tong, X.L., Wang, L., Gao, T.B., Qin, Y.G., Qi, Y.Q. and Xu, Y.P., 2009. Potential function of amniotic fluid in fetal development---novel insights by comparing the composition of human amniotic fluid with umbilical cord and maternal serum at mid and late gestation. J. Chin. med. Assoc., 72:368-373

Vicentea, J.S., Llobata, L., Viudes-de-Castrob, M.P., Lavaraa, R., Baselgaa, M. and Marco-Jiméneza, F., 2011. Gestational losses in a rabbit line selected for growth rate. Theriology, 77: 81-88.

Wahab, A., Hamayun, K., Shakoor, A., Qureshi, M.S., Muhammad, Y., Khan, S., Sadique, U. and Shah, M.K., 2016. Biochemical profile of local rabbits (Oryctolagus cuniculus) during successful pregnancy under backyard production system. Pakistan J. Zool., 48: 625-630. 